\title{
Feathery and network-like filamentous textures as indicators for the re-crystallization of quartz from a metastable silica precursor at the Rusey Fault Zone, Cornwall, UK
}

\author{
Tim I. Yilmaz ${ }^{1,2}$, Florian Duschl ${ }^{3}$, and Danilo Di Genova ${ }^{2,4}$ \\ ${ }^{1}$ Technical University Munich, Tectonics and Material Fabrics Section, Arcisstr. 21, 80333 Munich, Germany \\ ${ }^{2}$ Department of Earth and Environmental Sciences, Ludwig-Maximilians-Universität, Theresienstr. 41/III, \\ 80333 Munich, Germany \\ ${ }^{3}$ Geoscience Center of the University of Göttingen, Goldschmidtstr. 3, 37077 Göttingen, Germany \\ ${ }^{4}$ School of Earth Sciences, University of Bristol, Wills Memorial Building, Queens Road, Bristol, BS8 1RJ, UK \\ Correspondence to: Tim I. Yilmaz (tim.yilmaz@min.uni-muenchen.de)
}

Received: 31 March 2016 - Published in Solid Earth Discuss.: 5 April 2016

Revised: 14 October 2016 - Accepted: 19 October 2016 - Published: 7 November 2016

\begin{abstract}
Hydrothermal quartz crystals, which occur in the Rusey Fault Zone (Cornwall, UK), show feathery textures and network-like filamentous textures. Optical hotcathodoluminescence (CL) analysis and laser ablation inductively coupled plasma mass spectrometry (LA-ICP-MS) investigations on quartz samples revealed that positions exhibiting feathery textures (violet luminescence) contain higher amounts of $\mathrm{Al}$ and $\mathrm{Li}$ than quartz positions without feathery textures (blue luminescence), while concentrations of $\mathrm{Al}$ and Li are significantly lower in feathery textures. Both $\mathrm{Al}$ and Li correlate negatively with $\mathrm{Si}$. Raman spectroscopy investigations revealed the presence of a weak peak at 507$509 \mathrm{~cm}^{-1}$ in quartz affected by feathery textures, which we attribute to the presence of $\leq 5 \%$ moganite, a microcrystalline silica polymorph, intergrown with chalcedony. The combined occurrence of feathery textures and network-like filamentous textures in quartz samples from the Rusey Fault Zone points to the presence of a metastable silica precursor (i.e., amorphous silica or silica gel) before or during the crystallization.
\end{abstract}

\section{Introduction}

In the Rusey Fault Zone, hydrothermal quartz precipitated which shows (i) feathery textures and (ii) network-like filamentous textures. These microstructures occur in quartz coatings of so-called cockade-like quartz coatings (Frenzel and Woodcock, 2014). Feathery textures generally appear in blocky to subhedral quartz grains (Gebre-Mariam et al., 1993; Moncada et al., 2012; Henry et al., 2014), while network-like filamentous textures in general occur in microcrystalline chalcedony (Duhig et al., 1992; Grenne and Slack, 2003; Little et al., 2004). Both quartz and chalcedony precipitated under hydrothermal conditions. Feathery textures, microstructures commonly occurring in many hydrothermal quartz deposits, were first reported in quartz veins in Kingman, Arizona (Adams, 1920). Two models have been proposed to explain the origin of these textures: (i) epitaxial overgrowth of small quartz crystals on large existing quartz crystals (Dong et al., 1995) and (ii) re-crystallization from former fibrous, water-rich chalcedony (Sander and Black, 1988). Recently, Marinova et al. (2014) reported that feathery textures are generally accepted as being a re-crystallization product from chalcedony in the context of having a gel precursor.

Despite the recent advantages in studying these textures, our understanding of the origin of this texture is still incomplete, mostly because few data have been published. Here we report the obtained results from a multidisciplinary approach based on optical hot-cathodoluminescence (CL) analysis, laser ablation inductively coupled plasma mass spectrometry (LA-ICP-MS), and Raman spectroscopy investiga- 


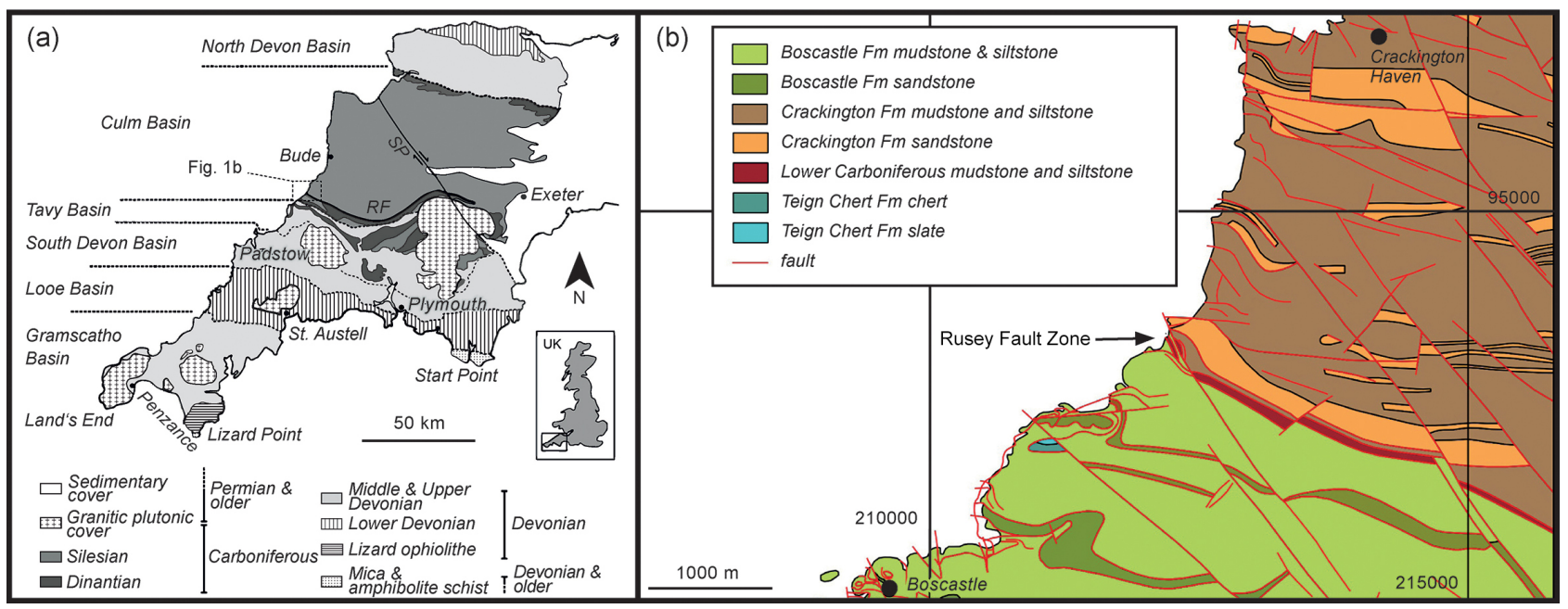

Figure 1. (a) Geological sketch map of Cornwall showing Devonian to pre-Devonian mica and amphibolite schists, Devonian to Carboniferous basins (indicated by short dashed lines), and Upper Carboniferous to Lower Permian granitic intrusions. Furthermore two structures, the Rusey Fault (RF) and the Sticklepath-Lustleigh Fault (SP), are indicated. The dashed rectangle indicates the position of Fig. 1b. Modified after Leveridge and Hartley (2006). (b) Geological and structural map of the Rusey Fault Zone area showing the Boscastle Formation to the south and Crackington Formation to the north of the Rusey Fault Zone. Most faults have an NW-SE to WNW-ESE trend; only a few faults have a NE-SW to ENE-WSW orientation. The position of the Rusey Fault Zone outcrop is indicated by the black arrow. Modified after British Geological Survey 1 : 50000 geological map (British Geological Survey, 2013).

tions on quartz crystals in order to obtain chemical insight into these microstructures.

\section{Geological setting}

The E-W-trending Rusey Fault is $\sim 100 \mathrm{~km}$ long and situated in the Carboniferous Culm Basin of Cornwall, UK (Fig. 1a). The studied outcrop ("Rusey Fault Zone") is positioned on the northern coast of Cornwall in metasediments of the Variscan foreland (Fig. 1b) at the contact between the Crackington and Boscastle formations of the Culm Basin (Shackleton et al., 1982). The Crackington Formation is made up of cycles of fine sediments (sandstones, siltstones, and mudstones) interpreted as parts of the lower Bouma sequences. The Boscastle Formation is made up of grey to dark grey and black slates with a relatively strong, slightly dipping cleavage that has been interpreted as segments of the upper Bouma sequences (Isaac and Thomas, 1998). Both formations have been considered as lateral counterparts of the Namurian in the Culm Basin (Thompson and Cosgrove, 1996). The British Geological Survey 1:50 000 geological map (British Geological Survey, 2013) (Fig. 1b) suggests that further fault-bounded lithological units of transitional nature between the Crackington Formation and the Boscastle Formation do exist at the studied outcrop on the coast.

The Rusey Fault is an important structure in Cornwall and has most likely had a long and complex history. Andrews et al. (1996) suggest that it originally started as an extensional fault during the development of the Culm Basin. It afterwards may have been reactivated as a post-peak metamorphic backthrust and became again an extensional fault at the end of the Variscan orogeny (Thompson and Cosgrove, 1996). Illite crystallinity studies (Primmer, 1985) suggest a temperature profile for the area between Tintagel and Bude, which indicate that the Boscastle Formation at the Rusey Fault Zone area reached epizonal metamorphic temperatures of $\sim 300^{\circ} \mathrm{C}$, whereas the Crackington Formation only reached anchizonal temperatures of $\sim 200^{\circ} \mathrm{C}$. Oxygen isotope investigations (Primmer, 1985) imply temperatures between 161 to $197^{\circ} \mathrm{C}$ north of the fault and temperatures $\geq 287^{\circ} \mathrm{C}$ south of the fault. Vitrinite reflectance data of the Boscastle Formation indicate a progressive increase in temperature as the Rusey Fault Zone is approached, suggesting that peak temperature close to the Rusey Fault Zone was $\sim 70^{\circ} \mathrm{C}$ higher than the metamorphic peak temperatures of the Boscastle Formation, thus implying flow of great amounts of hot fluids $\left(\sim 370^{\circ} \mathrm{C}\right)$ through the Rusey Fault Zone (Andrews et al., 1996).

\section{Methods}

\subsection{Cathodoluminescence (CL) microscopy}

CL is generally applied in a qualitative descriptive manner to classify and distinguish different minerals by their emission colors (Götze, 2002). CL emission is affected by lattice defects such as electron defects on broken bonds, vacancies, or radiation-induced defects and is related to trace activator ions such as $\mathrm{Fe}^{3+}, \mathrm{Cr}^{3+}, \mathrm{Al}^{3+}, \mathrm{Mn}^{2+}, \mathrm{Pb}^{2+}, \mathrm{Cu}^{2+}, \mathrm{Sn}^{2+}$ in addi- 

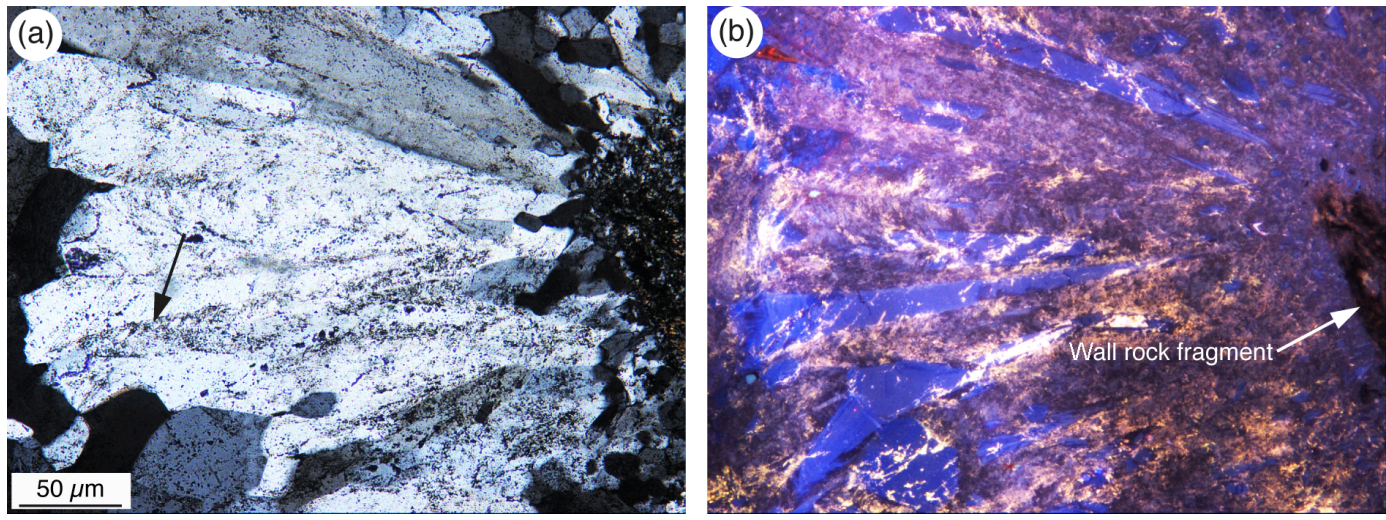

Figure 2. Photomicrographs of a quartz coating surrounding a wall rock fragment from the Rusey quartz zone: (a) X pol; (b) CL. (a) A wall rock fragment is surrounded by quartz, which increases in size from the fragment toward the left. The large comb quartz shows zones with densely distributed fluid inclusions (black arrow). (b) The CL image reveals that the comb quartz is made up by a core with partly euhedral faces. That core shows initial blue luminescence colors, a patchy area with violet luminescence is representing feathery textures, and yellow CL represents fluid inclusion trails (exposure time: 18.3 s) (non-oriented sample TY39X2).

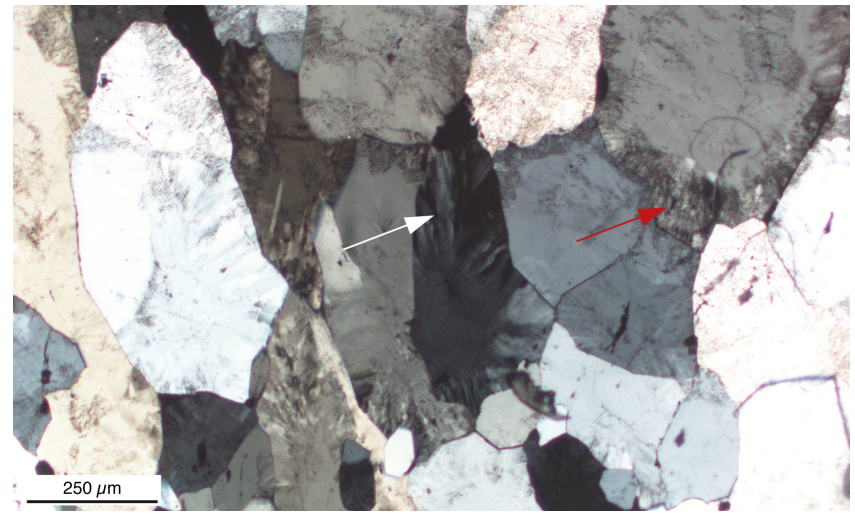

Figure 3. Photomicrograph of blocky anhedral to subhedral quartz crystals of the quartz coating from the quartz zone (Rusey Fault) showing feathery textures as indicated by the white arrow. The red arrow indicates feathery textures appearing within a zone in which a high amount of fluid inclusions is situated (non-oriented sample TY33X4; X pol).

tion to uranyl groups. CL can be used to detect quartz and to reveal the processes of crystal growth, deformation, recrystallization, and alteration (Götze et al., 2001). This method can reveal zoning features within (hydrothermal) quartz crystals and can help to identify various quartz generations (Ramseyer et al., 1988; Ramseyer and Mullis, 1990).

To visualize the internal structures and the growth and alteration features, and to detect different quartz types and generations, optical hot CL microscopy investigations were conducted using a CL microscope (HC3-LM Simon-Neuser; Neuser et al., 1995) coupled with a Kappa PS 40C-285 (DX) camera system with a resolution of $1.5 \mathrm{MP}$ attached to an Olympus BH-2 microscope at the University of Göttingen. An electron gun operated at $14 \mathrm{keV}$ under a high vacuum of $10^{-4}$ bar with a filament current running at $0.18 \mathrm{~mA}$ was used in which the electron beam diameter was $\sim 0.4 \mathrm{~cm}$. The uncovered and highly polished thin sections of representative samples were coated with a carbon layer for CL imaging. The exposure times were $4.9-22.2 \mathrm{~s}$ for the $5 \times$ objective, 12.6-22.2s for the $10 \times$ objective, and $37-46.5 \mathrm{~s}$ for the $20 \times$ objective. The detailed description of this method is given by Marshall (1988).

\subsection{LA-ICP-MS}

Trace element compositions of $\mathrm{SiO}_{2}$ minerals were determined from in situ investigation of a $200 \mu \mathrm{m}$ thick fluid wafer using a PerkinElmer Sciex Elan DRC2 ICP-MS. The apparatus was combined with a Lambda Physik Compex $110 \mathrm{ArF}$ Excimer laser ablation element working at $193 \mathrm{~nm}$ containing a low-volume sample chamber and an optical imaging system; Ar was used as the carrier gas. Before and after every laser ablation spot measurement, the background setting was recorded for $20 \mathrm{~s}$. Each of the 33 laser ablation spots was measured for $60 \mathrm{~s}$. The laser spot diameter was set to $23 \mu \mathrm{m}$, and the laser pulse repetition rate was $8 \mathrm{~Hz}$. All data were calibrated using the National Institute of Standards and Technology (NIST) external standard 610 (Pearce et al., 1997) and Si was used as a standard. ICP-MS data were processed using Iolite, the precision was calculated according to the formula $\frac{2 \times \sigma}{\sqrt{n}}$, and the error is below $5 \%$.

\subsection{Raman spectroscopy}

In this study we used Raman spectroscopy to study the spectral fingerprint of quartz and feathery textures in our samples. In comparison with other spectroscopic techniques such as infrared spectroscopy and X-ray fluorescence, Raman spectroscopy offers several advantages. Indeed, this technique is 

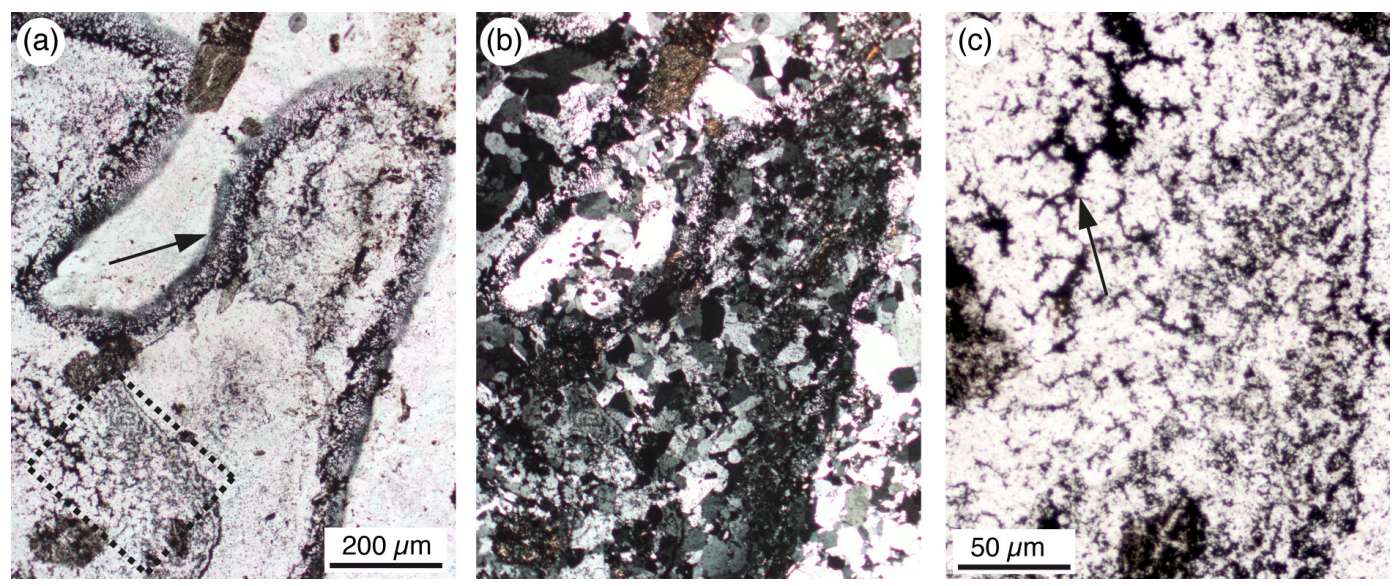

Figure 4. Photomicrographs of blocky anhedral to subhedral quartz from the quartz coating in the Rusey samples. (a) Network-like filamentous and/or dendritic textures are made up by dark pigments, most likely micrometer-sized iron oxides, which are restricted by a irregular and diffuse boundary (indicated by the black arrow); the rectangle indicates the position of (c); II pol. (b) Quartz is made up by blocky anhedral to subhedral quartz; X pol. (c) A zoom into the dense distribution of the particles reveals that the inclusions form a network-like or dendritic texture (black arrow); II pol. Oriented sample TY31C1.

non-destructive, requires little sample preparation, and allows for high-resolution investigation (in the order of microns). We acquired the Raman spectra using a micro-Raman spectrometer (HORIBA; XploRa-Raman-System) equipped with a green laser (Ar ion, $532 \mathrm{~nm}$ ). The beam provided an energy of $\sim 9.5 \mathrm{~mW}$ focused within a $50 \times$ objective on a spot of $\sim 1 \mu \mathrm{m}$. In order to achieve the highest spectral resolution (fundamental in this study to investigate both small shifts in wavelength and the development of shoulders), we used the maximum grating groove density (2400 lines $\mathrm{mm}^{-1}$ ), a confocal hole of $100 \mu \mathrm{m}$, and a slit of $100 \mu \mathrm{m}$. The exposure time was $10 \mathrm{~s}$ (5 times). Backscattered Raman radiation was collected from 50 to $700 \mathrm{~cm}^{-1}$. The elastically scattered photons were suppressed using a sharp edge filter. The system was calibrated using a silicon standard. No background correction was applied to the acquired spectra because the Raman signal showed no fluorescence background.

\section{Results and discussion}

The feathery textures in our samples are frequently arranged on the intragranular growth zoning of both anhedral to subhedral quartz grains and locally comb-shaped crystals (Fig. 2a, b). They are characterized by 5-20 $\mu \mathrm{m}$ sized subgrains, which appear as splintery or feathery patterns under a standard petrological microscope with crossed polarizers due to slight optical differences in maximum extinction positions (Fig. 3). Subgrains of the feathery textures are arranged along the $c$ axes in a sub-parallel arrangement to each other, forming filamentous bundles; the subgrain long-axes orientation within these bundles is perpendicular to the $c$ axis of the quartz core, a growth feature typically observed in chalcedony (Braitsch, 1957; Flörke et al., 1991). Locally they are restricted to growth zones and are accompanied by a high amount of fluid inclusions (Fig. 3).

Feathery textures are also accompanied by fluid inclusions (FI) that can be grouped into two types: (a) primary aqueous biphase FI within feathery textures (intragranular) (Figs. 2a, 3 ) and (b) secondary aqueous biphase FI that trace healed microfractures (intergranular). These microfractures affect both feathery textures and otherwise FI-free crystal cores. Typea inclusions occur along boundaries between subgrains or filamentous bundles. The shape of type-a inclusions is usually irregular or tubular-elongated with acicular ends, many of them are interconnected by minute channel-like features; type-b inclusions typically show irregular shapes. The size of fluid inclusions range from $<5$ to $10 \mu \mathrm{m}$.

Network-like filamentous textures are exhibited locally in quartz of the quartz coatings surrounding wall rock fragments (Fig. 4a-c). They are localized within a zone confined by a smooth irregular outline (Fig. 4a) and are characterized by fine $(<5 \mu \mathrm{m})$ irregular-shaped pigment inclusions probably composed of iron oxides (Fig. 4c). The pigment inclusions are not restricted by grain boundaries and occur within quartz exhibiting and not exhibiting feathery textures. These textures are similar to those described by Duhig et al. (1992) in chalcedony. The similarity to gel polymerization textures (Brinker and Scherer, 1985; Shih et al., 1989; Scherer, 1999) might indicate the relics of a polymerized material before overgrowth by blocky to subhedral and partly euhedral hydrothermal quartz.

\subsection{Cathodoluminescence (CL)}

The primary CL signal of quartz crystals from coatings exhibiting feathery textures is generally characterized by an intense blue (initial blue) core $(\sim 20-40 \%)$, which 

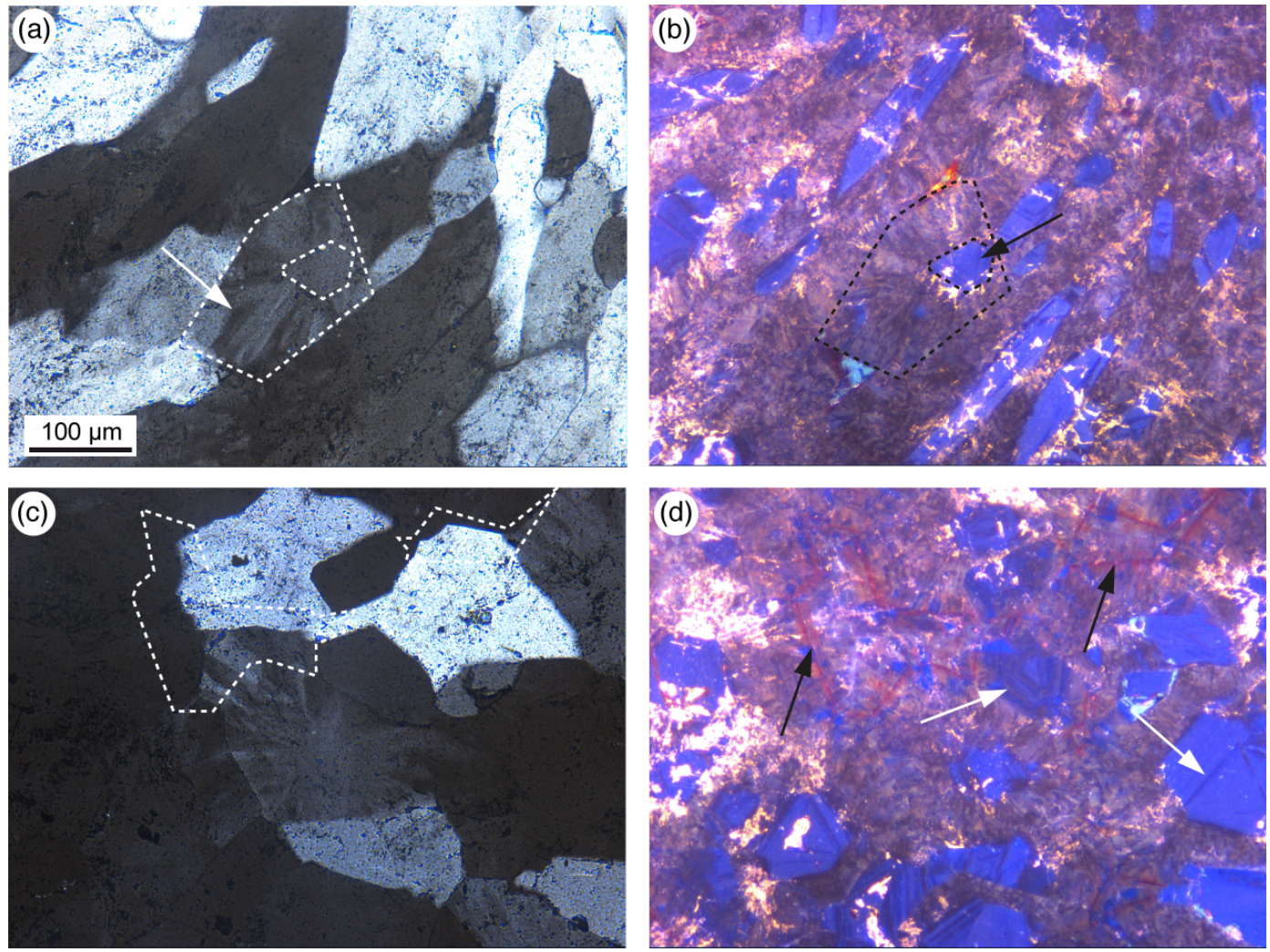

Figure 5. Photomicrographs (a, c) and CL images (b, d) of anhedral to subhedral quartz grains exhibiting feathery textures. (a) Splintery or fibrous appearance of feathery textures, as indicated by the white arrow. The outer dashed line indicates the grain boundaries of one quartz grain, and the inner dashed line indicates a core with no feathery textures; X pol. (b) CL in which the patchy area of the feathery textures is shown by violet to reddish-brown colored with bright blue patches; the core is shown by intense blue luminescence. The patchy violet area makes up $\sim 70-80 \%$ of the image (exposure time: $22.2 \mathrm{~s}$ ). (c) Photomicrograph of subhedral quartz grains locally showing feathery textures. The white dashed lines indicate intergranular zoning features (revealed in CL mode within d) X pol. (d) CL reveals red zoning features, which are indicated by black arrows. White arrows indicate growth zoning features within blue cores appearing in various shades of blue. The patchy violet area representing positions of feathery textures makes up 60-75\% of the image (exposure time: 18.3 s) (non-oriented sample TY39X2).

is surrounded by a violet to weak red to reddish-brown patchy area. This short-lived blue emission is usual for quartz growth in a hydrothermal environment (Ramseyer and Mullis, 1990; Perny et al., 1992; Götze et al., 2001). The blue core of the quartz grain shows locally euhedral faces (Fig. 2b) whereas the patchy area represents feathery textures made up by quartz fibers (Fig. 2a, b). Note that CL colors strongly depend on the duration and intensity of electron radiation (Ramseyer et al., 1988). In particular, within hydrothermal quartz, short-lived blue luminescence may disappear after several seconds of radiation (Fig. 5a-d). In our samples this transient blue CL lasts for $\sim 40 \mathrm{~s}$ under electron radiation. Besides, transient yellow CL significantly decreases in intensity after $\sim 60 \mathrm{~s}$ exhibiting an orange to red hue. The estimated percentage obtained by image analysis (Image J) of quartz exhibiting feathery textures is $\sim 60$ to $85 \%$ (Fig. $5 b$, d).
The patchy appearance of the feathery textures represents observed filamentous bundles under crossed polarized light. Grains with feathery textures locally show blue cores of hydrothermal quartz, which are locally highlighted by oscillatory growth zonings. These growth zonings appear in various shades of blue (Fig. 5d). Furthermore, red zoning features were observed, which are located within the feathery textures and in the blue cores (Fig. 5d). As they locally do affect both core and feathery textures within the same crystal, these red zoning features demonstrate the simultaneous growth of both quartz types. The quartz grains of the coating are traversed by fine irregular networks exhibiting bright yellow, transient CL (Fig. 5b, d).

CL of the network like filamentous textures do not show any difference from euhedral quartz and quartz cores in feathery textures (blue CL). 

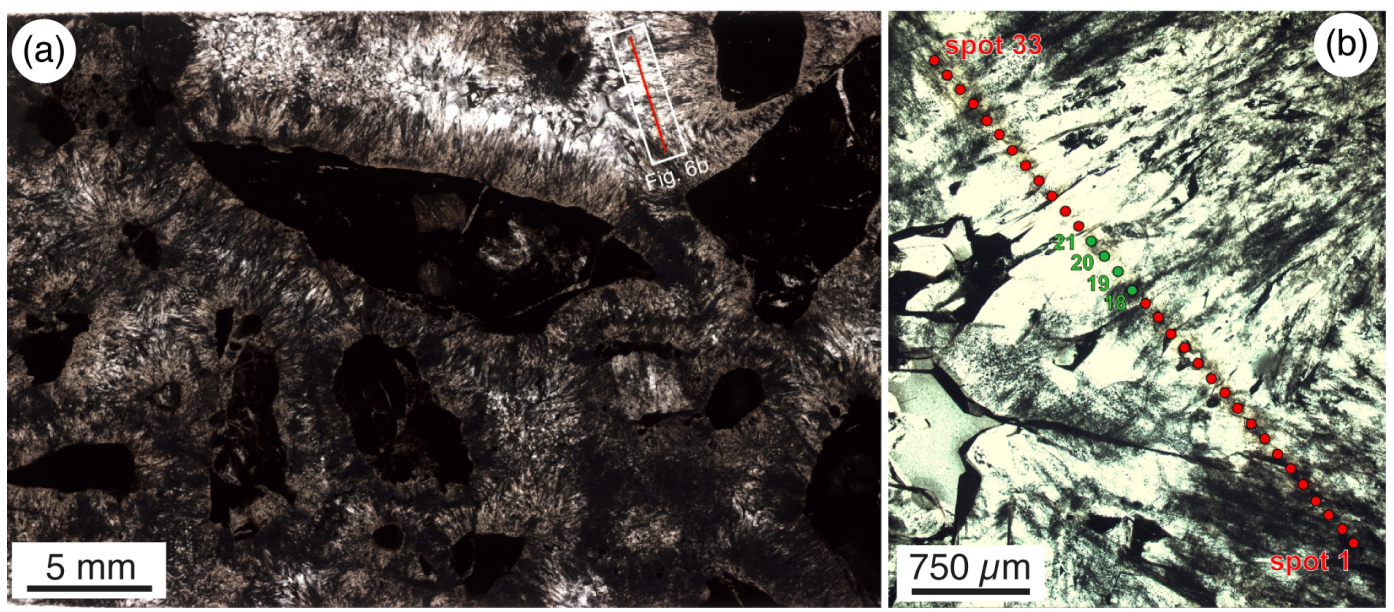

Figure 6. (a) Fluid wafer scan of angular to sub-rounded and quartz-coated gouge fragments from the quartz zone of the Rusey Fault Zone. The red line shows the analyzed LA-ICP-MS array. The white rectangle indicates the position represented in Fig. 6b, in which quartz grains with and without feathery textures have been investigated. (b) Measured LA-ICP-MS spots are indicated by red dots and spots on a single quartz grain for detailed analysis are marked by green dots (18 to 21). Oriented sample TY39X1, II pol.
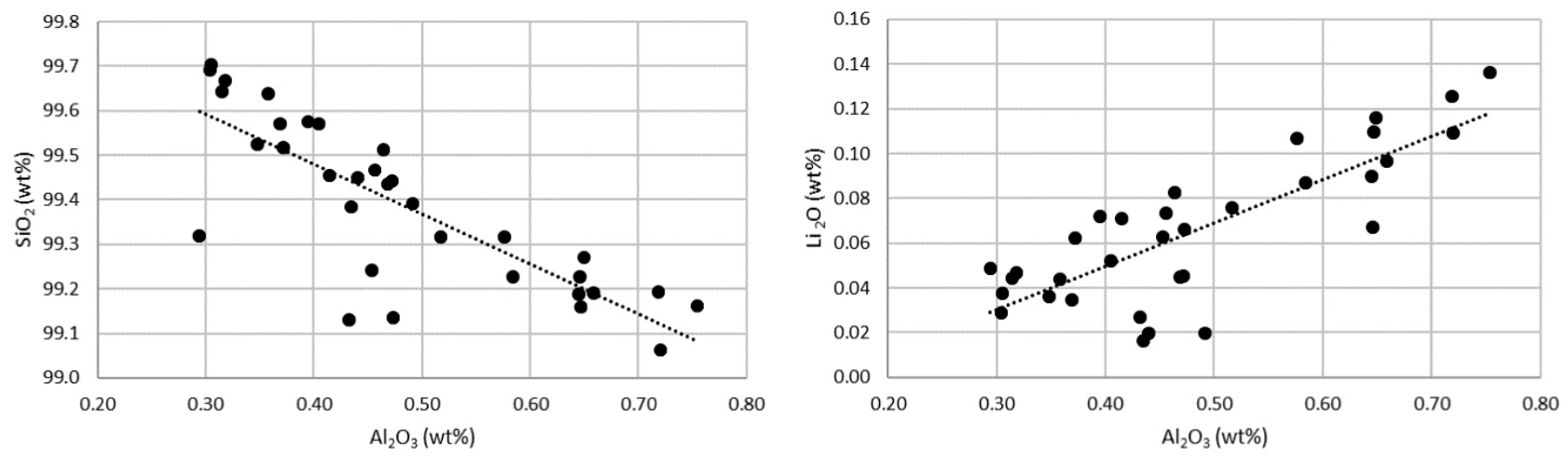

Figure 7. To illustrate fractionation trends between $\mathrm{Si}$ and substituting elements such as $\mathrm{Al}$ and Li the concentration of respective elements from all 33 measured spots were compared. The $\mathrm{SiO}_{2}$ vs. $\mathrm{Al}_{2} \mathrm{O}_{3}$ plot on the left reveals a negative correlation between $\mathrm{Si}$ and $\mathrm{Al}$ concentration in quartz in general, which may reflect a replacement of $\mathrm{Si}$ by $\mathrm{Al}$ and a monovalent cation. This observation is supported by the $\mathrm{Li}_{2} \mathrm{O}$ vs. $\mathrm{Al}_{2} \mathrm{O}_{3}$ plot on the right, which proves a positive correlation between $\mathrm{Li}$ and $\mathrm{Al}$.

\subsection{LA-ICP-MS}

A traverse of laser ablation spots within one fluid wafer (Fig. 6) was defined to examine the chemistry of the quartz grains in general, and more specifically to reveal differences in composition between quartz without feathery textures and quartz with locally well-developed feathery textures. As reported by several studies (Rusk et al., 2008; Flem and Müller, 2012; Rusk, 2012), the main substituent for $\mathrm{Si}^{4+}$ in quartz is $\mathrm{Al}^{3+}$ with $\mathrm{Li}^{+}$or $\mathrm{Na}^{+}$balancing the missing positive charge in the crystal lattice. Moreover, various other trace elements such as $\mathrm{B}, \mathrm{Ge}, \mathrm{Fe}, \mathrm{H}, \mathrm{K}, \mathrm{Na}, \mathrm{P}$, and Ti tend to be incorporated as lattice-bound impurities. Sb may also play a role, particularly in hydrothermal quartz (Rusk et al., 2011). Other commonly occurring elements including $\mathrm{Ca}, \mathrm{Cr}, \mathrm{Cu}, \mathrm{Mg}, \mathrm{Mn}, \mathrm{Pb}$, $\mathrm{Rb}$, and $\mathrm{U}$ are suggested to be input from fluid or solid inclu- sions, which may occasionally influence mass spectrometric analysis (Müller et al., 2003; Flem and Müller, 2012).

Within the array of laser ablation spots shown in Fig. 6, the $\mathrm{Si}$ content showed slight variation throughout the measured part of the fluid wafer with $\mathrm{SiO}_{2}$ contents varying between 99.06 and $99.7 \mathrm{wt} \%$. Al and Li show a clear positive correlation, and both elements correlate negatively with Si (Fig. 7). The intensities of Sb vary slightly but essentially remain stable over the entire array; a weak negative correlation of $\mathrm{Sb}$ with $\mathrm{Si}$ could be observed. Ti shows relatively low concentrations in general $\left(0.0002\right.$ to $\left.0.0042 \mathrm{wt} \% \mathrm{TiO}_{2}\right)$ and only a weak correlation with $\mathrm{Si}$ could be detected. Elements such as $\mathrm{Ca}, \mathrm{Na}, \mathrm{Mg}$, and $\mathrm{K}$ are abundant within cores and feathery textures, but measured concentrations are in general low. Though the peaks of these elements correlate locally, no cor- 


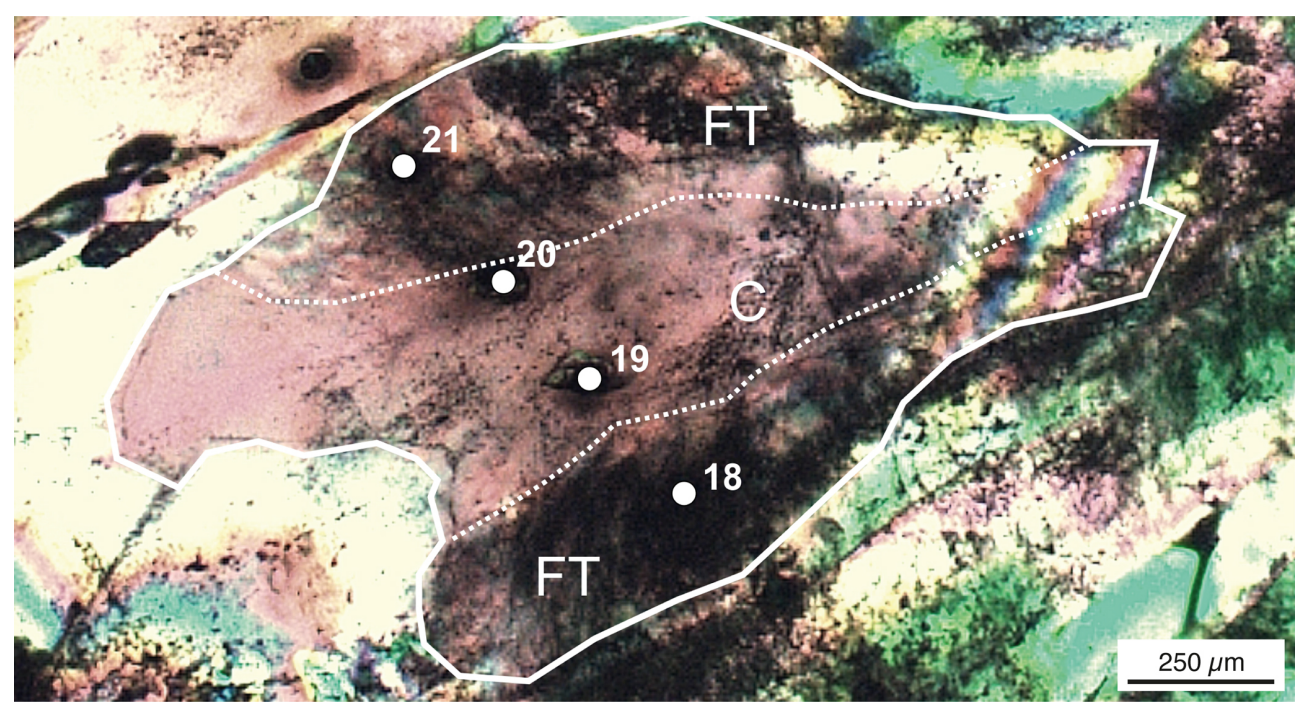

Figure 8. Detail of a single quartz grain exhibiting a clear quartz core without feathery textures (C) surrounded by feathery textures (FT). Both areas were analyzed using LA-ICP-MS in order to directly compare quartz composition on a single grain. A solid white line outlines the quartz grain, while the dotted white lines delimit core and feathery texture sections. Spots 18 and 21 completely hit feathery textures, spots 19 and 20 affected feathery texture-free quartz only. Anomalous quartz interference colors are due to the fact that the fluid wafer has a thickness of about $200 \mu \mathrm{m}$. Oriented sample TY39X1, X pol.

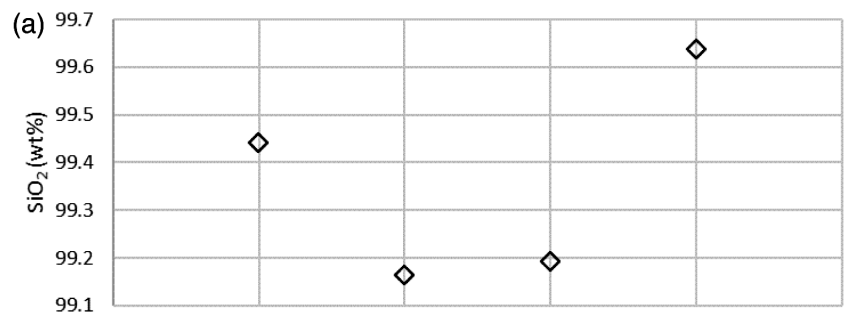

(b)
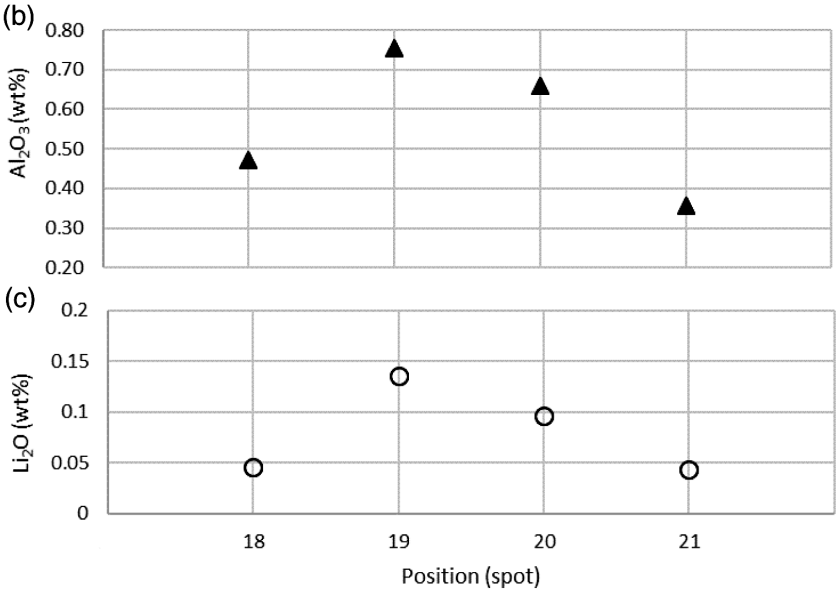

Figure 9. Three concentration plots illustrating the distribution of $\mathrm{Si}$ (a), $\mathrm{Al}$ (b) and Li (c) across the area shown in Fig. 8. Both $\mathrm{Al}$ and Li show a positive correlation and do correlate negatively with Si. Obviously the clear quartz core (spots 19 and 20) contains more $\mathrm{Al} / \mathrm{Li}$ than quartz with feathery textures (spots 18 and 21), while $\mathrm{Si}$ at the same time shows lower concentrations. relation between named elements and $\mathrm{Al}$ and/or $\mathrm{Li}$ could be detected.

The detailed analysis of single quartz grains exhibiting both feathery textures and a feathery-texture-free core, using LA-ICP-MS, supports the previously observed correlation between $\mathrm{Al}, \mathrm{Li}$, and $\mathrm{Si}$, where $\mathrm{Al}$ and $\mathrm{Li}$ probably replace $\mathrm{Si}$ in the crystal lattice (an example is shown in Fig. 6b, spots 18 to 21, and Fig. 8). This replacement mostly affects the feathery-texture-free cores, as high $\mathrm{Al}$ and $\mathrm{Li}$ concentrations prove, while quartz with feathery textures obviously incorporated significantly lower amounts of $\mathrm{Al}$ and $\mathrm{Li}$ (Fig. 9). Other elements typically found in quartz show no significant characteristics. A compilation of major and trace element concentrations is given in Table S1 in the Supplement.

\subsection{Raman spectroscopy}

Samples from the quartz zone of the Rusey Fault, specifically the quartz coatings surrounding wall rock and gouge fragments, were analyzed in order to examine the origin of the feathery textures. The obtained Raman spectra collected from the feathery textures exhibit different spectral signatures with respect to the quartz spectra. Over three different thin sections we conducted $\sim 70$ measurements in quartz grains exhibiting feathery textures. Initially the measurements were performed using a grating with 1200 lines $\mathrm{mm}^{-1}$. Results were not unequivocally positive or negative, so no significant difference (i.e., development and/or shift in Raman peaks) could be determined between the quartz and the moganite spectra in feathery textures. For this reason we decided to maximize the spectral resolution of our mea- 


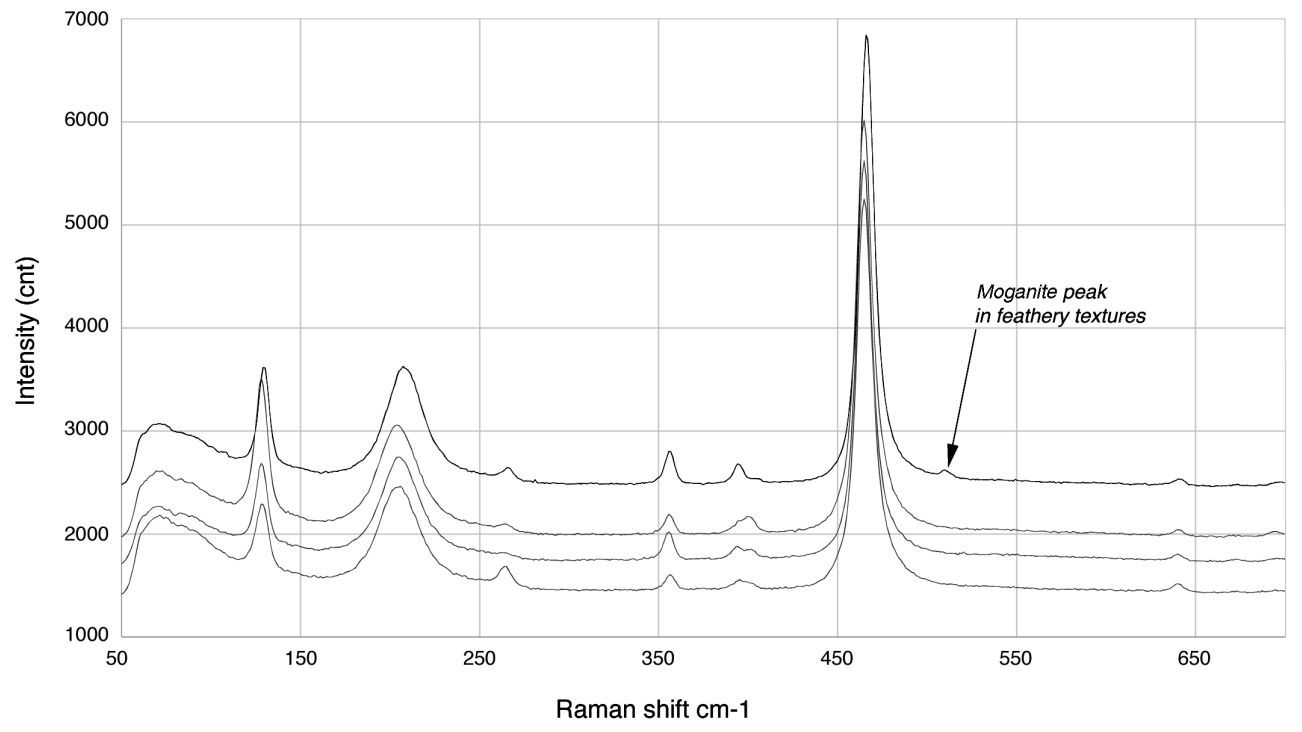

Figure 10. Raman bands of $\mathrm{SiO}_{2}$ samples from the Rusey Fault Zone: representative Raman spectrum from feathery textures from a quartz coating in the Rusey Fault Zone showing a peak at $\sim 507 \mathrm{~cm}^{-1}$ (dark Raman spectrum); Raman spectra from euhedral quartz from a quartz coating in the Rusey Fault Zone showing no peak at $\sim 507 \mathrm{~cm}^{-1}$ (grey spectra).

surements acquiring Raman spectra using a grating with 2400 lines $\mathrm{mm}^{-1}$. In Fig. 8 we report a selection of the Raman spectra from quartz and feathery textures acquired over the samples. The main quartz band systematically shifts from $\sim 464$ to $\sim 467 \mathrm{~cm}^{-1}$ in the region where feathery textures were observed. Moreover, two other bands located at the lowwavenumber region show a shift in the same direction (i.e., to higher wavenumbers). In particular, the bands located at $\sim 128$ and $\sim 203 \mathrm{~cm}^{-1}$ shifted to 130 and $208 \mathrm{~cm}^{-1}$. Importantly, a new peak at $\sim 507-509 \mathrm{~cm}^{-1}$ was detected within the feathery textures regions and not within the crystal cores (Fig. 10). The development of this peak in the spectra of the feathery textures region was not possible to absolutely discern when using the 1200 lines $\mathrm{mm}^{-1}$ grating because it was incorporated in the tail of the main quartz peak. Furthermore we performed our measurements using polarizers on quartz crystals with different $c$ axis orientations to explore the changes of Raman features due to the crystal orientation (Fig. S1 in the Supplement). This was necessary to rule out the Raman peak at $\sim 507-509 \mathrm{~cm}^{-1}$ in feathery textures not being related to changes of the $c$ axis orientation.

The origin of feathery textures may be explained with the re-crystallization of former fibrous, water-rich, chalcedony. Chalcedony is microcrystalline silica composed of nanoscale intergrowths of $\alpha$-quartz and moganite (Heaney, 1993). Within chalcedony and other microcrystalline silica varieties between 5 and $20 \mathrm{wt} \%$ of moganite may crystallize (Heaney and Post, 1992). Raman spectroscopy investigations performed on $\mathrm{SiO}_{2}$ samples from hydrothermal deposits, cherts, and flints have demonstrated that moganite in microcrystalline quartz/chalcedony can be detected (Kingma and Hemley, 1994; Hopkinson et al., 1999; Götze et al., 1998, 1999;
Rodgers and Cressey, 2001; Rodgers and Hampton 2003; Pop et al., 2004; Rodgers et al., 2004; Heaney et al., 2007; Schmidt et al., 2012, 2013; Sitarz et al., 2014). Results show that the main Raman bands are located at 462-465 and 500$503 \mathrm{~cm}^{-1}$ for $\alpha$-quartz and chalcedony with different wt $\%$ of moganite, respectively. Indeed, Schmidt et al. (2013 and references therein) showed that moganite band positions shift to higher wavenumbers with decreasing wt $\%$ moganite content dispersed in a chalcedony sample (Fig. 3a in Schmidt et al., 2013). Based on these results we attribute the peak $\sim 507 \mathrm{~cm}^{-1}$ to be the moganite peak. Moreover, a possible calibration issue can explain the slight discrepancy between our data and some literature results. Indeed, a possible variation of Raman peaks position can be associated with the non-linearity of the used spectrometer. The linearity during our calibration procedure was defined by the laser position (zero position) and the Koeff value (LabSpec 5 software standard procedure). This latter parameter was calculated starting from the well-known position of the main silicon band $\left(520.7 \mathrm{~cm}^{-1}\right)$. When comparing Raman features from different spectrometers, particular attention has to be paid to other Raman systems and software that use different approaches to correct for nonlinearity. In this study, the spectral region of interest (i.e., quartz and moganite bands) is located at higher wavenumber than the calibration one $\left(0-520.7 \mathrm{~cm}^{-1}\right)$. Therefore, the small discrepancy (a systematic shift to higher frequency of both quartz and moganite Raman peak position) we observed can be ascribed to some non-linear effect due to the calibration procedures.

A comparison of the spectra obtained from Rusey samples with those obtained from literature (e.g., Götze et al., 1998; Pop et al., 2004; Schmidt et al., 2013) allows us to 
conclude that within feathery textures a re-crystallization of chalcedony took place in our samples. Moreover, according to the calibration of Götze et al. (1998) based on the Raman band integral ratio of the quartz and moganite bands, a maximum of $5 \mathrm{wt} \%$ of moganite intergrown with chalcedony can be estimated.

\section{Conclusions}

Based on the results and discussion presented above we draw the following conclusions: (1) laser ablation measurements indicate that the irregular distribution of elements such as $\mathrm{Ca}, \mathrm{Mg}, \mathrm{Na}$, and $\mathrm{K}$ within the observed quartz types may be caused by fluid and solid inclusions. Short-lived blue CL is related to the substitution of $\mathrm{Si}$ with $\mathrm{Al}(+\mathrm{Li})$ in the crystal lattice (Ramseyer and Mullis, 1990). Red to violet CL colors within feathery textures are most likely caused by point defects (non-bridging oxygen hole centers) (Marfunin, 1979; Kalceff and Phillips, 1995; Götze et al., 2009) and not by incorporation of interstitial cations (Ramseyer et al., 1988; Ramseyer and Mullis, 1990; Götze et al., 2005). The formation of primary fluid inclusions was likely favored by the recrystallization (i.e., dissolution and precipitation) of a silica polymorph (moganite and/or chalcedony) to quartz (Goldstein and Rossi, 2002), as (CL-) microscopy of microfabrics suggests. The Ti values, which are sometimes below the detection limit, indicate re-crystallization temperatures below $400{ }^{\circ} \mathrm{C}$ (Götte and Ramseyer, 2012). Relatively low re-crystallization temperatures $\left(<300^{\circ} \mathrm{C}\right)$ are also confirmed by the presence of intense yellow CL along feathery texture subgrains and microcracks (Ioannou et al., 2004; Rusk et al., 2008). Though LA-ICP-MS analysis did not reveal essential differences in composition between observed quartz types, the obvious correlation in $\mathrm{Al} / \mathrm{Li}$ and $\mathrm{Si}$ concentrations proves a different incorporation mechanism of respective elements that cannot be explained by varying $P / T$ conditions, since both quartz types formed simultaneously. Either the re-crystallization of feathery textures may have caused a depletion of $\mathrm{Al}$ and $\mathrm{Li}$ within the crystal lattice, or the quartz precursor did contain lower amounts of respective elements (growth-direction controlled incorporation) (Ramseyer and Mullis, 1990). Yellow CL in the Rusey samples indicates high concentrations of lattice defects, probably generated by the rapid crystallization of a non-crystalline precursor (Götze et al., 1999). (2) Raman spectroscopy revealed the occurrence of a weak peak at $507-509 \mathrm{~cm}^{-1}$ (Fig. 10), which we attribute to the presence of $\leq 5 \mathrm{wt} \%$ of moganite intergrown with chalcedony within the feathery textures. (3) The presence of locally occurring network-like filamentous textures (Fig. $4 \mathrm{a}-\mathrm{c}$ ), which have appearances similar to polymerization structures (Scherer, 1999), may indicate a polymerization stage of a possible silica gel phase (Duhig et al., 1992). (4) The presence of (a) feathery textures and (b) network-like textures indicate the re-crystallization from (a) a microcrys- talline silica polymorph (moganite and/or chalcedony) and (b) a metastable $\mathrm{SiO}_{2}$ phase (e.g., amorphous silica or silica gel) (Oehler, 1976; Sander and Black, 1988; Duhig et al., 1992; Marinova et al., 2014). As this study is based on analyses of natural samples, hydrothermal crystallization experiments should be carried out to investigate growth conditions of feathery and network-like filamentous textures.

\section{The Supplement related to this article is available online at doi:10.5194/se-7-1509-2016-supplement.}

Acknowledgements. We are grateful to Jörn H. Kruhl for plenty of helpful discussions and Alfons van den Kerkhof for his support during CL measurements and interpretation, as well as to Klaus Simon for LA-ICP-MS measurements and his expertise. We also thank Ottomar Krentz for field work support, Melanie Kaliwoda and Rupert Hochleitner for Raman measurements at the Mineralogical State Collection Munich (SNSB), Klaus Mayer for sample cutting and preparation, and Moritz Wiegand (Bureau Mirko Borsche) for his support in graphic design. A detailed and thoughtful review by Brian Rusk and two anonymous reviewers strongly improved the manuscript. This study was financially supported by the German Academic Exchange Service (DAAD) within the Australia-Germany Joint Research Cooperation Scheme (project 56267246). Tim Ibrahim Yilmaz gratefully acknowledges financial support by the Leonhard Lorenz Foundation (grant no. 826/12) and the TUM Graduate School (TUM GS). Please contact the corresponding author for access to the raw Raman spectra as well as to the LA-ICP-MS data that this study is based upon.

This work was supported by the German Research Foundation (DFG) and the Technische Universität München within the funding programme

Open Access Publishing.

Edited by: F. Rossetti

Reviewed by: B. Rusk and two anonymous referees

\section{References}

Adams, S. F.: A microscopic study of vein quartz, Econ. Geol., 15, 623-664, 1920.

Andrews, J. R., Day, J., and Marshall, J. E. A.: A thermal anomaly associated with the Rusey Fault and its implications for fluid movements, Proc. Ussher, 9, 68-71, 1996.

Braitsch, O.: Über die natürlichen Faser- und Aggregationstypen beim $\mathrm{SiO}_{2}$, ihre Verwachsungsformen, Richtungsstatistik und Doppelbrechnung, Heidelberger Beiträge zur Mineralogie und Petrographie, 5, 331-372, 1957.

Brinker, C. J. and Scherer, G. W.: Sol $\rightarrow$ ggel $\rightarrow$ glass: I. Gelation and gel structure, J. Non-Cryst. Solids, 70, 301-322, 1985.

British Geological Survey: Digital Geological Map of Great Britain $1: 50000$ scale (DiGMapGB-50) data, Keyworth, Nottingham, tiles ew322, 2013. 
Dong, G., Morrison, G., and Jaireth, S.: Quartz textures in epithermal veins, Queensland - classification, origin, and implication, Econ. Geol., 90, 1841-1856, 1995.

Duhig, N. C., Stolz, J., Davidson, G. J., and Large, R. R.: Cambrian microbial and silica gel textures in silica iron exhalites from the Mount Windsor volcanic belt, Australia; their petrography, chemistry, and origin, Econ. Geol., 87, 764-784, 1992.

Flem, B. and Müller, A.: In situ analysis of trace elements in quartz using laser ablation inductively coupled plasma mass spectroscopy, in: Quartz: Deposits, Mineralogy and Analytics, edited by: Götze, J. and Moeckl, R., Springer, 219-236, 2012.

Flörke, O. W., Graetsch, H., MArtin, B., Röller, K., and Wirth, R.: Nomenclature of micro- and non-crystalline silica minerals based on structure and microstructure, Neues Jb. Miner. Abh., 163, 19-42, 1991.

Frenzel, M. and Woodcock, N. H.: Cockade breccia: Product of mineralisation along dilational faults, J. Struct. Geol., 68, 194206, 2014

Gebre-Mariam, M., Groves, D. I., McNaughton, N. J., Mikucki, E. J., and Vearncombe, J. R.: Archaean Au-Ag mineralisation at Racetrack, near Kalgoorlie, Western Australia: a high crustallevel expression of the Archaean composite lode-gold system, Miner. Deposita, 28, 375-387, 1993.

Goldstein, R. H. and Rossi, C.: Recrystallization in Quartz Overgrowth, J. Sediment. Res., 72, 432-440, 2002.

Götte, T. and Ramseyer, K.: Trace Element Characteristics, Luminescence Properties and Real Structure of Quartz, in: Quartz: Depositis, Mineralogy and Analytics, edited by: Götze, J. and Möckel, R., Springer, Berlin, Heidelberg, 265-285, 2012.

Götze, J.: Potential of cathodoluminescence (CL) microscopy and spectroscopy for the analysis of minerals and materials, Anal. Bioanal. Chem., 374, 703-708, 2002.

Götze, J., Nasdala, L., Kleeberg, R., and Wenzel, M.: Occurrence and distribution of "moganite" in agate/chalcedony: a combined micro-Raman, Rietvield, and cathodoluminescence study, Contrib. Mineral. Petr., 133, 96-105, 1998.

Götze, J., Plötze, M., Fuchs, H., and Habermann, D.: Defect structure and luminescence behaviour of agate-results of electron paramagnetic resonance (EPR) and cathodoluminescence (CL) studies, Mineral. Mag., 63, 149-163, 1999.

Götze, J., Plötze, M., and Habermann, D.: Origin, spectral characteristics and practical applications of the cathodoluminescence (CL) of quartz - a review, Miner. Petrol., 71, 225-250, 2001.

Götze, J., Plötze, M., and Trautmann, T.: Structure and luminescence characteristics of quartz from pegmatites, Am. Mineral., 90, 13-21, 2005.

Götze, J., Möckel, R., Kempe, U., Kapitonov, I., and Vennemann, T.: Characteristics and origin of agates in sedimentary rocks from the Dryhead area, Montana, USA, Mineral. Mag., 73, 673-690, 2009

Grenne, T. and Slack, J. F.: Bedded jaspers of the Ordovician Løkken ophiolite, Norway: seafloor deposition and diagenetic maturation of hydrothermal plume-derived silica-iron gels, Mineral. Deposita, 38, 625-639, 2003.

Heaney, P. J.: A proposed mechanism for the growth of chalcedony, Miner. Petrol., 115, 66-74, 1993.

Heaney, P. J. and Post, J. E.: The Widespread Distribution of a Novel Silica Polymorph in Microcrystalline Quartz Varieties, Science, 255, 441-443, 1992.
Heaney, P. J., McKeown, D. A., and Post, J. E.: Anomalous behavior at the I2/a to Imab phase transition in $\mathrm{SiO}_{2}$-moganite: An analysis using hard-mode Raman spectroscopy, Am. Moneral., 92, 631-639, 2007.

Henry, A. D., McInnes, P., and Tosdal, R. M.: Structural Evolution of Auriferous Veins at the Endeavour 42 Gold Deposit, Cowal Mining District, NSW, Australia, Soc. Econom. Geol., 109, 1051-1077, 2014.

Hopkinson, L., Roberts, S., Herrington, R., and Wilkinson, J.: The nature of crystalline silica from the TAG submarine mound, $26^{\circ}$ N Mid Atlantic Ridge, Miner. Petrol., 137, 342-350, 1999.

Ioannou, S. E., Götze, J., Weiershäuser, L., Zubowski, S. M., and Spooner, E. T. C.: Cathodoluminescence characteristics of Archean volcanogenic massive sulfide related quartz: Noranda, Ben Nevis and Matagami districts, Abitibi Subprovince, Canada, Geochem. Geophys. Geosys., 5, 1-24, 2004.

Isaac, K. P. and Thomas J. M.: Chapter 5 - Carboniferous, in: Selwood, Edwin Brian, Eric Michael Durrance, and Colin Malcolm Bristow, The geology of Cornwall: and the Isles of Scilly, University of Exeter, 1998.

Kalceff, S. M. A. and Phillips, M. R.: Cathodoluminescence microcharacterization of the defect structure of quartz, Phys. Rev. B, 52, 3122-3135, 1995.

Kingma, K. J. and Hmeley, R.: Raman spectroscopic study of microcrystalline silica, Am. Mineral., 79, 269-273, 1994.

Leveridge, B. and Hartley, A. J.: The Vasican Orogony: the development and deformation of Devonian/Carboniferous basins in SW England and South Wales, in: The geology of England and Wales, edited by: Brenchley, P. J. and Rawson, P. F., Geological Society, London, 225-255, 2006.

Little, C. T. S., Glynn, S. E. J., and Mills, R. A.: Four-Hundredand-Ninety-Million-Years Record of Bacteriogenic Iron Oxide Precipitation at Sea-Floor Hydrothermal Vents, Geomicrobiol. J., 21, 41-429, 2004.

Marfunin, A. S.: Spectroscopy luminescence and radiation centers in minerals, Springer, New York, 356 pp., 1979.

Marinova, I., Ganev, V., and Titorenkova, R.: Colloidal origin of colloform-banded textures in the Paleogene low-sulfidation Khan Krum gold deposit, SE Bulgaria, Miner. Deposita, 49, 49-74, 2014.

Marshall, D. J.: Cathodoluminescence of geological materials, Allen and Unwin, 146 pp., 1988.

Moncada, D., Mutchler, S., Nieto, A., Reynolds, T. J., Rimstidt, J. D., and Bodnar, R. J.: Mineral textures and fluid inclusion petrography of the epithermal Ag-Au depositis at Guanajuato, Mexico: Application to exploration, J. Geochem. Explor., 114, 20-35, 2012.

Müller, A., Wiedenbeck, M., van den Kerkhof, A. M., Kronz, A., and Simon, K.: Trace elements in quartz - a combined electron microprobe, secondary ion mass spectrometry, laser ablation ICP-MS, and cathodoluminescence study, Eur. J. Mineral., 15, 747-763, 2003.

Neuser, R. D., Bruhn, F., Götze, J., Habermann, D., and Richter, D. K.: Kathodolumineszenz: Methodik und Anwendung, Zbl. Geol. Pal., 1, 287-306, 1995.

Oehler, J. H.: Hydrothermal crystallization of silica gel, Geol. Soc. Am. Bull., 87, 1143-1152, 1976.

Pearce, N. J., Perkins, W. T., Westgate, J. A., Gorton, M. P., Jackson, S. E., Neal, C. R., and Chenery, S. P.: A compilation of new and 
published major and trace element data for NIST SRM 610 and NIST SRM 612 glass reference materials, Geostandard. Newsletter, 21, 115-144, 1997.

Perny, B., Eberhardt, P., Ramseyer, K., Mullis, J., and Pankrath, R.: Microdistribution of $\mathrm{Al}, \mathrm{Li}$, and $\mathrm{Na}$ in alpha quartz; possible causes and correlation with short-lived cathodoluminescence, Am. Mineral., 77, 534-544, 1992.

Pop, D., Constantina, C., Tätar, D., and Kiefer, W.: Raman spectroscopy on gem-quality microcrystalline and amorphous silica varieties from Romania, Studia UBBB Geologia, 49, 41-52, 2004.

Primmer, T.: A transition from diagenesis to greenschist facies within a major Variscan fold/thrust complex in south-west England, Mineral. Mag., 49, 365-374, 1985.

Ramseyer, K. and Mullis, J.: Factors influencing short-lived blue cathodoluminescence of alpha-quartz, Am. Mineral., 75, 791800, 1990.

Ramseyer, K., Baumann, J., Matter, A., and Mullis, J.: Cathodoluminescence colours of $\alpha$-quartz, Mineral. Mag., 52, 669-677, 1988.

Rodgers, K. A. and Cressey, G.: The occurrence, detection and significance of moganite $\left(\mathrm{SiO}_{2}\right)$ among some silica sinters, Mineral. Mag., 65, 157-167, 2001.

Rodgers, K. A. and Hampton, W. A.: Laser Raman identification of silica phases comprising microtextural components of sinters, Mineral. Mag., 67, 1-13, 2003.

Rodgers, K. A., Browne, P. R. L., Buddle, T. F., Cook, K. L., Greatrez, R. A., Hampton, W. A., Herdianita, N. R., Holland, G. R., Lynne, B. Y., Martin, R., Newton, Z., Pastras, D., Sannazarro, K. L., and Teece, C. I. A.: Silica phases in sinters and residues from geothermal fields of New Zealand, Earth-Sci. Rev., 66, 1-61, 2004.

Rusk, B.: Cathodoluminescence textures and trace elements in hydrothermal quartz, in: Quartz: deposits, mineralogy and analytics, edited by: Götze, J. and Moeckl, R., Springer, Berlin, Heidelberg, 307-329, 2012.
Rusk, B., Koenig, A., and Lowers, H.: Visualizing trace element distribution in quartz using cathodoluminescence, electron microporbe, and laser ablation inductively coupled mass spectrometry, Am. Mineral., 96, 703-708, 2011.

Rusk, B. G., Lowers, H. A., and Reed, M. H.: Trace elements in hydrothermal quartz: relationships to cathodoluminescence textures and insight into vein formation, Geology, 36, 547-550, 2008.

Sander, M. V. and Black, J. E.: Crystallization and recrystallization of growth-zoned vein quartz crystals from epithermal systems; implications for fluid inclusion studies, Econ. Geol., 83, 1052 1060, 1988.

Scherer, G. W.: Structure and properties of gels, Cement Concrete Res., 29, 1149-1157, 1999.

Schmidt, P., Slodczyk, A., Léa, V., Davidson, A., Puaud, S., and Sciau, P.: A comparitve study of the thermal behaviour of lengthfast chalcedony, length-slow chalcedony (quartzine) and moganite, Phys. Chem. Miner., 40, 331-340, 2012.

Schmidt, P., Bellot-Gurlet, L., Léa, V., and Sciau, P.: Moganite detection in silica rocks using Raman and infrared spectroscopy, Eur. J. Mineral. 25, 797-805, 2013.

Shackleton, R. M., Ries, A. C., and Coward, M. P.: An interpretation of the Variscan structures in SW England, J. Geol. Soc., 139, 533-541, 1982.

Shih, W.-H., Liu, J., Shih, W. Y., Kim, S. I., Sarikaya, M., and Aksay, I. A.: Mechanical Properties of colloidal gels, MRS Proceedings, 155, doi:10.1557/PROC-155-83, 1989.

Sitarz, M., Wyszomirski, P., Handke, B., and Jeleń, P.: Moganite in selected Polish chert samples: The evidence from MIR, Raman and X-ray studies, Spectrochim. Acta A, 122, 55-58, 2014.

Thompson, E. and Cosgrove, J. W.: The Structural and regional setting of the rocks of the Rusey Headland, Proc. Ussher, 9, 133$135,1996$. 